\title{
STUDI RANCANGAN PEMBANGKIT LISTRIK TENAGA MIKROHIDRO (PLTMH) PADA ALIRAN SUNGAI CISADANE DI KELURAHAN KERANGGAN
}

\author{
Novy Hapsari ${ }^{1)}$, Sri Yatmani $^{2)}$, Herbert Rajagoekgoek ${ }^{3)}$, \\ Ratnawati $^{4}$, Ulfatul Faiza ${ }^{5)}$ \\ 1,2,3,4,5 Program Studi Teknik Elektro, Institut Teknologi Indonesia \\ email: novy.hapsari@iti.ac.id
}

\begin{abstract}
The need for electricity has increased every year. One of the most popular supply of electrical energy is electrical energy from energy sources flowing and plunging water, called as the Micro Hydro Power Plant (PLTMH). Cisadane River is one of the major rivers with length around 80 kilometers and crosses 44 districts in 5 regencies / cities, including desa Kranggan, South Tangerang. Therefore, community service is carried out in an effort to utilize and optimize the flow of the Cisadane river. The Study of PLTMH design for community service program was conducted. Data of river flow, altitude and location of the river flow will be collected so that it can be calculated and observed for the design of PLTMH that best suits the efficiency of the largest electrical energy, which is obtained using the TurbinPro software program. PLTMH planning chose to use a propeller/kaplan turbine because of its low head which is 4 meters. The power generated is $994 \mathrm{~kW}$ at a maximum head with an efficiency of $91.2 \%$ and a river flow of $52.26 \mathrm{~m} 3 / \mathrm{s}$ and at a minimum head of $601 \mathrm{~kW}$ with an efficiency of $82.2 \%$ and a discharge of $47.56 \mathrm{~m} 3 / \mathrm{s}$.
\end{abstract}

Keywords: electrical energy, community service program, PLTMH, power generation, Kaplan turbine

\section{PENDAhUluan}

Penyediaan energi listrik yang sangat populer saat ini adalah energi listrik yang berasal dari sumber energi aliran dan terjun air. Salah satu jenis pembangkit listrik yang memanfaatkan aliran dan terjun air sebagai pemutar turbin, sehingga mampu menggerakkan poros generator dan akhirnya menghasilkan energi listrik adalah Pembangkit Listrik Tenaga Mikrohidro (PLTMH) (Arismunandar, 1974).

Sungai Cisadane merupakan salah satu sungai besar yang daerah aliran seluruhnya sekitar 154.654 Ha dan melintasi 44 kecamatan di 5 (lima) kabupaten/kota yaitu Kabupaten Bogor, Kota Bogor, Kab. Tangerang, Kota Tangerang, dan Tangerang Selatan, termasuk salah satunya adalah desa Kranggan.

Atas dasar inilah dilakukan pengabdian masyarakat yang diawali dengan perencanaan Pembangkit Listrik Tenaga Mikrohidro (PLTMH) pada aliran sungai Cisadane di Kelurahan Keranggan yang selanjutnya dapat dimanfaatkan sebagai sarana pembelajaran (eduwisata) sekaligus sumber tenaga listrik bagi masyarakat sekitar. Pengabdian kepada masyarakat ini berisi pembahasan perencanaan PLTMH, dimulai dari survei lokasi, penentuan lokasi intake, bagaimana aliran air sungai dapat menggerakkan turbin dan generator, dan penentuan rumah pembangkit untuk mendapatkan tinggi jatuh (head) optimum dan juga aman dari banjir, serta perhitungan daya keluaran yang akan di hasilkan serta pemilihan turbin dan generator yang akan digunakan dan juga PLTMH di sungai Cisadane ini akan dijadikan tempat edukasi bagi warga sekitar.

\section{METODE}

Pengabdian masyarakat ini dilakukan pada Sungai Cisadane, Kelurahan Keranggan Kecamatan Setu, Kota Tangerang Selatan, Banten, dimana gambar area Kelurahan Keranggan diperlihatkan pada Gambar 1 berikut.

Gambar 1. Peta lokasi Kelurahan Keranggan 
Langkah pelaksanaan diawali dengan pengumpulan data untuk memilih rncangan yang paling sesuai untuk daerah aliran sungai Cisadane pada Kelurahan Keranggan.

Data primer yang dipakai untuk mendukung pelaksanaan survei data pada pengabdian masyarakat ini antara lain:

1. Data luas penampang Sungai Cisadane, Kelurahan Keranggan Kecamatan Setu, Kota Tangerang Selatan, Banten.

2. Data kecepatan aliran pada Sungai Cisadane, Kelurahan Keranggan Kecamatan Setu, Kota Tangerang Selatan, Banten.

3. Data tinggi air Sungai Cisadane, Kelurahan Keranggan Kecamatan Setu, Kota Tangerang Selatan, Banten.

Gambar 2. berikut adalah gambar pelaksanaan pengambilan data di pinggir sungai Cisadane, desa Keranggan.

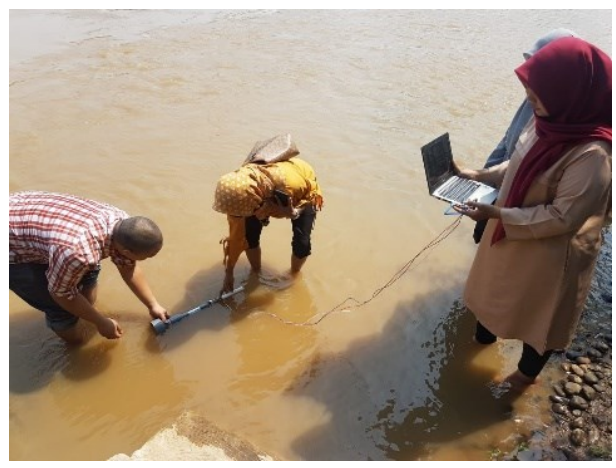

Gambar 2. Pengukuran debit air aliran sungai Cisadane

Alat-alat berikut digunakan sebagai pendukung pelaksanaan studi kajian, yakni antara lain:

1. Selang plastik transparan ukuran $1 / 4$ “ ukuran 10- 20 meter

2. Alat ukur debit air, dimana dibuat sebuah alat yang berfungsi untuk mengukur jumlah volume aliran air sungai per detiknya. Alat tersebut diperlihatkan pada Gambar 3.

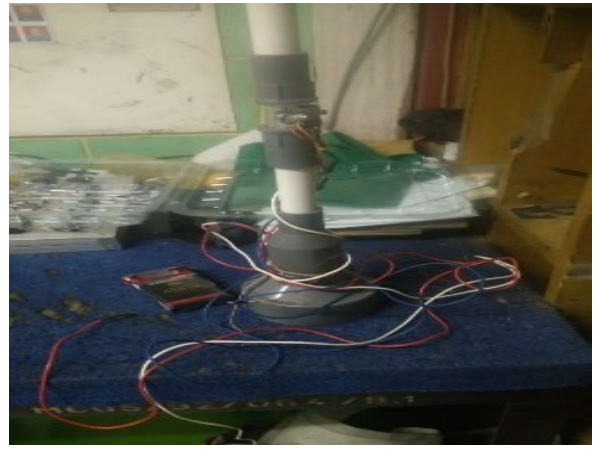

Gambar 3. Alat ukur debit air

3. Alat ukur ketinggian air

4. Mistar ukur dan meteran

5. Botol air mineral

6. Stopwatch

7. Peralatan tulis

8. Software Turbin Pro, merupakan software simulator yang membantu menentukan bentuk rancangan paling memungkinkan untuk aliran sungai Cisadane di daerah Kelurahan Keranggan.

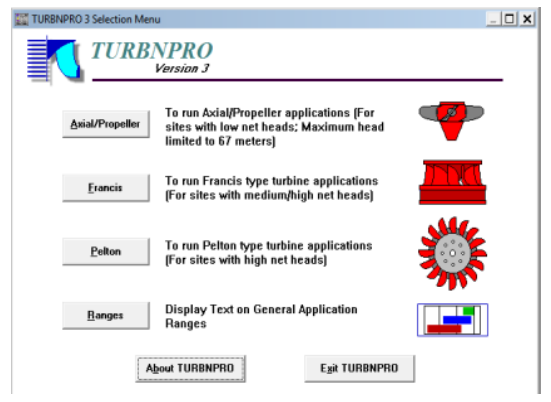

Gambar 4. Software TurbinPro sebagai simulator

Data-data yang dibutuhkan untuk simulasi pembuatan desain turbin adalah (TurbinPro, 2000):

1. Debit air adalah mengukur dengan metode float di sungai pada saat musim kemarau.

2. Net head adalah perbedaan antara total head di pintu masuk turbin dan total head pada keluar turbin draft tube (total head menjadi jumlah potensial, kepala tekanan dan kecepatan)

3. Site gross adalah perbedaan maksimum yang mungkin dalam elevasi antara headwater (H.W.) dan tailwater (T.W.)

4. Ketinggian elevasi adalah ketinggian situs di atas permukaan laut digunakan untuk menentukan atmosfer atau barometrik pressure head (Hatm) untuk koefisien kavitasi (sigma) dan unit pengaturan $(\mathrm{Hs})$ perhitungan

5. Suhu air digunakan untuk menentukan kepala tekanan uap air (Hvp) untuk 
perhitungan koefisien kavitasi (sigma) dan pengaturan satuan (Hs).

6. Pengaturan (Hs) tailwater adalah perbedaan ketinggian garis tengah turbin dan tailwater minimum

7. Prioritas efisiensi menentukan di mana di sepanjang rentang operasi turbin debit pengenal akan terjadi.

8. Rasio head ini adalah parameter yang menetapkan di mana, dalam kisaran head kapabilitas solusi, net head terukur (sebelumnya dimasukkan) akan terjadi Frekuensi.

9. Frekuensi, program akan memilih solusi turbin yang dirancang hanya untuk beroperasi di kecepatan sinkron yang kompatibel dengan frekuensi sistem yang dimasukkan.

10. Min Net Head Karena kemungkinan variasi level headwater, level tailwater, dll, bersih kepala di situs mungkin jatuh di bawah kepala bersih dinilai.

Metode yang digunakan untuk mengukur nilai debit aliran air sungai berdasarkan data survei digunakan metode float, dimana metode ini dapat digunakan apabila aliran air cenderung lurus, tidak beriak atau bergelombang dan tidak banyak halangan pada saluran air, dengan menggunakan sebuah benda yang dapat melayang di dalam aliran air dan mengalir bersama aliran air.

Kecepatan rata-rata aliran air tersebut kemudian dikoreksi dengan mengalikannya dengan faktor koreksi tertentu sesuai dengan kondisi yang ada pada aliran sungai sesuai pada tabel 1 .

Tabel 1. Faktor koreksi (Sukamta, 2013)

\begin{tabular}{lc}
\hline Sungai / Saluran & Faktor koreksi \\
\hline $\begin{array}{l}\text { Sungai besar, lurus, lambat, } \\
\text { dan tidak banyak halangan }\end{array}$ & 0,75 \\
$\begin{array}{l}\text { Saluran bersemen, lurus, dan } \\
\text { bentuknya teratur }\end{array}$ & 0,85 \\
$\begin{array}{l}\text { Saluran bersemen, dangkal, } \\
\text { lurus, dan bentuknya teratur }\end{array}$ & 0,8 \\
$\begin{array}{l}\text { Sungai kecil, lurus, dan } \\
\text { banyak halangan } \\
\text { Sungai dangkal dan } \\
\text { bergelombang }\end{array}$ & 0,65 \\
$\begin{array}{l}\text { Sangat dangkal dan } \\
\text { bergelombang }\end{array}$ & 0,45 \\
\hline
\end{tabular}

Luas area yang dilalui oleh aliran air diukur dengan cara mengukur sisi-sisi aliran air dan kedalaman rata-rata saluran dan kemudian dihitung luasnya. Setelah didapatkan luas area yang dilalui oleh sungai maka debit aliran air dapat dengan mudah dihitung dengan mengalikan kecepatan ratarata yang telah dikoreksi oleh faktor koreksi dengan luas area yang dilalui oleh aliran air secara cross-section. (Sukamta, 2013), dengan formula sebagai berikut:

$$
\mathrm{Q}=\mathrm{V} . \mathrm{A} . \mathrm{F} \text {. }
$$

Dimana :

$$
\begin{aligned}
& \mathrm{Q}=\text { debit air }\left(\mathrm{m}^{3} / \text { det }\right) \\
& \mathrm{V}=\text { kecepatan aliran }(\mathrm{m} / \mathrm{det}) \\
& \mathrm{A}=\text { luas penampang aliran }\left(\mathrm{m}^{2}\right) \\
& \mathrm{F}=\text { Faktor koreksi sesuai kondisi saluran } \\
& \text { / sungai. }
\end{aligned}
$$

\section{HASIL DAN PEMBAHASAN}

\section{Data Survey Studi Kelayakan}

Pengukuran dimulai dengan pengukuran debit air sungai, dilakukan minimalnya satu tahun dan debit air menjadi acuan adalah debit minimal pada musim kemarau, dimana diambil data debit sungai Cisadane di Kelurahan Keranggan tahun 2013-2017 dari Badan Balai Wilayah Sungai selain dengan melakukan pengukuran langsung sebagai data sekunder.

Penentuan debit dilakukan dengan optimalisasi antara debit yang terukur pada saat survei dengan mempertimbangkan perkiraan debit pada musim kemarau. Disamping itu perhitungan debit dengan metoda float dengan alat ukur debit air dipergunakan untuk mendukung perhitungan, sehingga didapatkan debit aliran air sebesar $30,91391 \mathrm{~m}^{3} / \mathrm{s}$.

Data masukan untuk masukan simulasi program TurbinPro diambil pada saat musim kemarau dengan debit air sebesar 30,91391 $\mathrm{m}^{3} / \mathrm{s}$. Dari data di lapangan head efektifnya 1,7 meter dan head lokasi 4 meter yang pengukuran dilakukan pada saat musim penghujan. Oleh karena itu besarnya head efektif minimum ini diperoleh dengan mengasumsikan besarnya adalah $85 \%$ dari head efektif (Sukamta, 2013). Dengan demikian head efektif minimum adalah $85 \%$ $\times 1,7$ meter $=1,445$ meter. Sementara itu, data elevasi lokasi diperoleh dari pengukuran langsung ke lokasi dengan alat ukur altimeter dan data temperatur air diperoleh dari pengukuran langsung dengan menggunakan termometer.

Data keadaan lokasi tersebut dimasukkan ke data entry form dengan turbin jenis axial/propeller dan selanjutnya terdapat pilihan solusi ukuran dan karakter turbin yang memungkinkan serta perkiraan potensi daya mekanik yang dihasilkan sesuai dengan data 
masukan seperti Gambar 5.

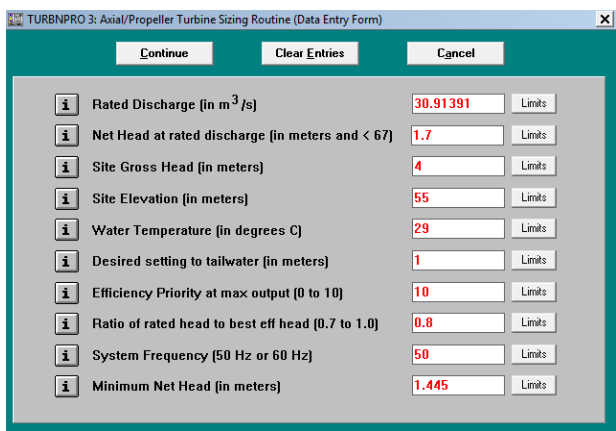

Gambar 5. Data masukan untuk TurbinPro

Setelah menentukan ukuran turbin, selanjutnya menentukan bentuk dan susunan turbin. Jenis susunan pit/bulb, horizontal axis yang dipilih adalah tipe bulb. Selanjutnya pada penentuan susunan turbin dengan menentukan jenis pengaturan turbin. Pengaturan turbin yang dipilih adalah jenis Kaplan.

\section{Hasil solusi turbin}

Setelah menentukan susunan turbin, terdapat data solusi turbin disertai karakteristik dan daya guna turbin dari solusi petama dapat dilihat pada Gambar 6. Dapat diamati efisiensi terbaik saat nominal pada head efektif rata-rata dengan dengan nilai $94 \%$ dicapai pada debit $30,85 \mathrm{~m}^{3} / \mathrm{s}(99,8 \%$ dari debit rata-rata $30,85 \mathrm{~m}^{3} / \mathrm{s}$ ) dengan daya yang diperoleh $484 \mathrm{~kW}$.

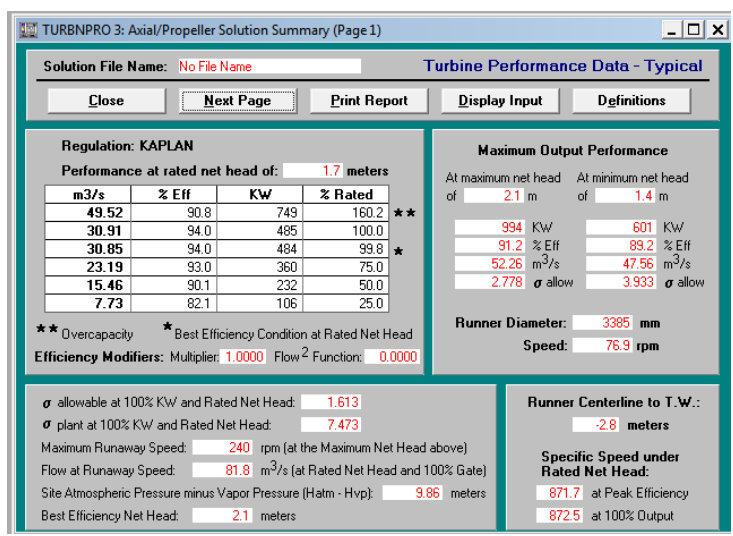

Gambar 6. Hasil data jenis bulb tipe Kaplan.

Saat beban nol pada head efektif maksimum, kecepatan putaran turbin bernilai $240 \mathrm{rpm}$. Ini merupakan rating over speed turbin yang harus diperhatikan saat pemilihan generator. Pada saat kaplan terbuka maksimum pada head efektif rata-rata, debit yang mengalir lewat turbin sebesar $81,8 \mathrm{~m}^{3} / \mathrm{s}$. Hal tersebut akan menimbulkan kavitasi pada ketinggian 9,86 meter. Ketinggian maksimum terbaik terjadi pada 2,1 meter, dimana daya yang dihasilkan sebesar $994 \mathrm{~kW}$ dan ketinggian minimum pada 1,4 meter yaitu daya yang dihasilkan sebesar $601 \mathrm{~kW}$.

Desain turbin, saluran luaran turbin, susunan turbin dan generator yang sesuai dengan data masukan paling optimal dan pengolahan menggunakan simulator TurbinPro menghasilkan bentuk dan ukuran generator seperti diilustrasikan pada gambar 7 dan 8 dibawah ini.

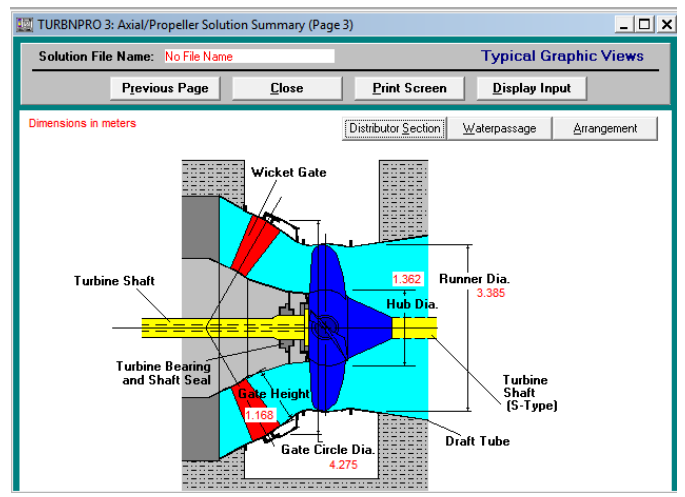

Gambar 7. Bagian dan konstruksi rancangan generator jenis Bulb dengan tipe Kaplan

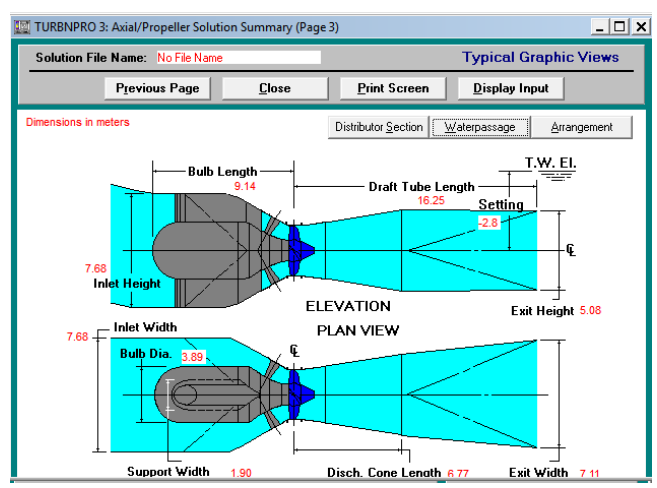

Gambar 8. Aliran air jenis Bulb dengan tipe Kaplan.

Pada Gambar 4.4 ditampilkan kurva efisiensi daya guna turbin pada berbagai debit dengan nilai head efektif yang tetap (crossplot). Dengan melihat gambar tersebut daya guna terjadi jika ketinggiannya 1,7 meter, maka turbin dihitung dari debit tertinggi yaitu $40 \mathrm{~m}^{3} / \mathrm{s}$ sampai debit terendah yaitu $7,4 \mathrm{~m}^{3} / \mathrm{s}$, tetapi pada ketinggian $1,7 \mathrm{~m}$ tidak didapatkan efisiensi kondisi yang terbaik. Sedangkan jika pada ketinggian 1,5 meter maka debit tertingginya yaitu $38,8 \mathrm{~m}^{3} / \mathrm{s}$ sampai debit terendah yaitu $7,5 \mathrm{~m}^{3} / \mathrm{s}$ dengan kondisi efisiensi terbaik di $93,3 \%$ dan debit sebesar $29.92 \mathrm{~m}^{3} / \mathrm{s}$ dengan daya output sebesar $400 \mathrm{~kW}$. 


\section{KESIMPULAN}

Studi rancangan PLTMH pada aliran sungai Cisadane untuk pemanfaatan eduwisata berdasarkan survei dan pengambilan data selama pelaksanaan pengabdian masyarakat di desa Kranggan menghasilkan:

1. Perencanaan PLTMH memilih dengan meggunakan turbin propeller/kaplan dikarenakan headnya yang rendah yaitu 4 meter

2. Debit yang digunakan dengan metode float sebesar $30,91391 \mathrm{~m}^{3} / \mathrm{s}$ dan tinggi jatuh 1,7 meter dihasilkan daya mekanik sebesar $471 \mathrm{~kW}$.

3. Dari hasil simulasi didapatkan daya yang dihasilkan paling maksimal dengan menggunakan turbin tipe bulb dengan pengaturan kaplan.

4. Daya guna terjadi jika ketinggiannya 1,7 meter, maka turbin dihitung dari debit tertinggi yaitu $40 \mathrm{~m}^{3} / \mathrm{s}$ sampai debit terendah yaitu $7,4 \mathrm{~m}^{3} / \mathrm{s}$. Sedangkan jika pada ketinggian 1,5 meter maka debit tertingginya yaitu $38,8 \mathrm{~m}^{3} / \mathrm{s}$ sampai debit terendah yaitu $7,5 \mathrm{~m}^{3} / \mathrm{s}$ dengan kondisi efisiensi terbaik di $93,3 \%$ dan debit sebesar $29.92 \mathrm{~m}^{3} / \mathrm{s}$ dengan daya output sebesar $400 \mathrm{~kW}$.

\section{UCAPAN TERIMA KASIH}

Ucapan terima kasih ditujukan pada Lembaga Pengabdian Pada Masyarakat (LP2M) Institut Teknologi Indonesia yang telah memberikan hibah sehingga pengabdian masyarakat untuk Kelurahan Keranggan dapat berjalan dengan baik.

\section{REFERENSI}

Abdussalam, Rafika. 2015. Analisis Potensi Sungai Atep Oki Serta Desain Dasar Bangunan Sipil Untuk Pembangkit Listrik Tenaga Air. 2 (5)

Arismunandar dan Susumumu Kuwahara, 1974. Pembangkitan Dengan Tenaga Air. Buku Pegangan Teknik Tenaga Listrik, Jilid I, Pradnya Paramita, Jakarta

Akhmad Syarief, Hajar Isworo. "Simulasi Turbin Air Kaplan pada PLTMH di Sungai Sampanahan Desa Magalau Hulu Kabupaten Kotabaru," Proceeding
Seminar Nasional Tahunan Teknik Mesin XIV (SNTTM XIV), vol. 2

Damanik, A. 2009. Pedoman Studi Potensi. Dijen ESDM. Jakarta

Firman Jamali. 2014. "Studi Perencanaan Pembangkit Listrik Tenaga Minihidro Berbantuan Program Turbinpro di Desa Sinar Pekayau Kecamatan Sepauk Kabupaten Sintang," in Jurnal, Universitas Tanjungpura.

Indarto. A, P.T. Juwono, dan Rispiningtati. 2012. Kajian potensi sungai Srinjing untuk pembangkit listrik tenaga mikrohidro (pltmh) brumbung di Kabupaten Kediri. Jurnal Teknik Pengairan.

Kadir R. 2010. Perancangan pembangkit listrik tenaga mikro hidro (PLTMH) di sungai marimpa kecamatan pinembani. Skripsi. Universitas Tadulako. Kota Palu

Mayong Personal Site.2006. Metode pengukuran Debit Aliran. 18 Desember 2006

Moona Mohammadi, Mohammadreza Mohammadi, Alireza Mohammadi, and Said Farahat. July 2016. Analyzing Mathematical and Software Methods for Selecting and Designing Francis Turbine in Hydropower Plants. Jurnal of Clean Energy Technologies, vol. 4.

Nurkhaerani, Fatma. 2016. Perancangan pembangkit Listrik Tenaga Mikro Hidro (PLTMH) di Sungai Cikaniki, Desa Malasari, Kecamatan Nanggung, Kabupaten Bogor. Skripsi. Institut Pertanian Bogor

Patty, O.F. 1995. Tenaga Air. Penerbit Erlangga,Surabaya.

Rompas, 2011. Analisis Pembangkit Listrik Tenaga Mikrhidro (PLTMH) pada Daerah Aliran Sungai Ongkak Mongondow di Desa Muntoi Kabupaten Bolaang Mongondow. Volume 16. Nomor 2.

S. d. K. A. Sukamta. 2013. Perencanaan Pembangkit Listrik Tenaga Tenaga Mikro Hidro (PLTMH) Jantur Tabalas Timur. Teknik Elektro Universitas. Semarang

Version 3, TurbnPro, "user's guide," 2000.

Waisnawa S. 2012. Pemilihan jenis turbin pada pembangkit listrik tenaga mikro hidro (PLTMH). Jurnal Matrix.

Zuhal. 1991. Dasar Tenaga Listrik. Penerbit ITB. Bandung 